\title{
DSM Controversies, Defining the Normal and the Paraphilia: Sexual Pleasure Objects, Fantasy, Variations, Soft-BDSM, ESR, Hypersexuality, Sex Addiction and Nymphomania
}

ISSN: 2578-0042

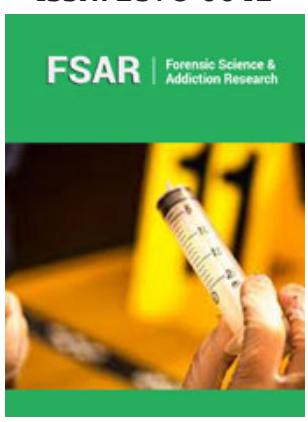

*Corresponding author: Ümit Sayin $\mathrm{H}$, Associate Professor, Institute of Forensic Sciences, Cerrahpașa-İstanbul, President of Asehert-Ciseated, Director of SexuS Journal, Turkey

Submission: 韭June 02, 2019

Published: 侮August 06, 2019

Volume 5 - Issue 1

How to cite this article: Ümit Sayin $\mathrm{H}$, DSM Controversies, Defining the Normal and the Paraphilia: Sexual Pleasure Objects, Fantasy, Variations, Soft-BDSM, ESR, Hypersexuality, Sex Addiction and Nymphomania. Forensic Sci Add Res. 5(1). FSAR.000608.2019.

DOI: 10.31031/FSAR.2019.05.000608

Copyright@ Ümit Sayin H, This article is distributed under the terms of the Creative Commons Attribution 4.0 International License, which permits unrestricted use and redistribution provided that the original author and source are credited.
Ümit Sayin $H^{*}$

Institute of Forensic Sciences, İstanbul University-Cerrahpasa, Turkey

\begin{abstract}
In sexuality research and sex therapy, it is generally very difficult to define "the normal" and to differentiate variations, mild and harmless fantasies, sexual games and fantasy role play from paraphilia. In DSM classifications, there are still dilemmas, misinterpretations, contradictions and controversies to define paraphilias and what pathology is and what is not. There are new definitions and terminology in sexuality research, such as "Expanded Sexual Response" (ESR), "status orgasmus" "Never Ending Orgasms (Super Orgasms)", "Deep Vaginal Erogenous Zones” (DVZ),"Sexual Pleasure Objects” (SEPOs), "Hypersexuality" "Non-genital orgasms" and "soft-non-pathological BDSM" etc. In this review novel definitions of some new notions are given and it is discussed why those sexual behaviors cannot be regarded as a pathology or paraphilia, such as "Hypersexuality" and soft-BDSM; a unified definition of paraphilias is proposed. Sometimes, ESR women are often confused with pathological hypersexuality. ESR is defined as: "being able to attain long lasting and/or prolonged and/or multiple and/or sustained orgasms and/or status orgasmus that lasted longer and more intense than the classical orgasm patterns defined in the literature". Lately a research performed in United Kingdom revealed that the research team had discovered more than 500 women who were having more than 30 to 50 orgasms in one or two hours (see: You Tube, "Never Ending Orgasm" documentary). We have concluded in many publications that during an ESR orgasm and status orgasmus, some women can have trains of tens of orgasms in a given love making session. Women can be trained to achieve ESR orgasms and it is a learned phenomenon. Although defined recently in medical literature, the notion of ESR is as old as history, starting from the Dionysus Cult Era and Far Eastern sexual traditions descending from Early Ages and Tantra and Taoist cultures. At the turn of 21st Century, Female Orgasm is still a mystery and we only know the tip of the Orgasmic Iceberg of Females.
\end{abstract}

Keywords: Sexual pleasure objects; Fantasy; Variations; Soft-BDSM; ESR; Hypersexuality; Nymphomania; Paraphilia; DSM-5; Normal; EQ; Sexual intelligence; SEPO

\section{Introduction}

When it comes to define "normal sexuality" it is an extremely difficult task, because "the normal" on sexual behavior has changed depending upon the era, century, society, culture, climate conditions, and belief systems. During the end of $19^{\text {th }}$ century, "female orgasm" was regarded as pathology, coined as "hysterical paroxysm" (Please refer to the comedy film "Hysteria"); doctors used a vaginal-clitoral massage technique to heal this "epilepsy-like paroxysm" or "mental sickness", by inducing orgasm in these hysteria-conversion cases. However, in the $6^{\text {th }}$ century before Christ, during the Era of Greek and Hellenist cultures, and also in the Far East Cultures, "female orgasm" was regarded very normal and essential for the women's health [1-8]. The term "orgasm" comes from the Greek word ORGIA (orgiasmorgiasmus-orgasmus-orgasm), a feast and celebration, which was practiced during the harvest festivals in the Dionysus Cult, particularly in the Elite secretive town of Eleusis $[9,10]$. Taoist and Tantric literature is full of the different definitions of female orgasm starting from $2^{\text {nd }}$ century B.C. and $2^{\text {nd }}-7^{\text {th }}$ centuries A.D. to middle ages of the Far East, centuries before when "female orgasm" was considered as mental sickness by medical doctors and academic circles in the $19^{\text {th }}$ Century in the West [1-5,9-15]. 
Most of the perversions and paraphilias were defined by Kraft Ebbing, a forensic psychiatrist, by the end of $19^{\text {th }}$ century, in his famous book Psychopathic Sexualis [16] in which the terms like sadism, masochism, fetishism, masturbation etc. were introduced and defined; homosexuality and lesbian behavior, masturbation, even female ejaculation were defined as extreme pathologies in Psychopathia Sexualis [16]. Until 1974, homosexuality was accepted as a perversion and paraphilia by APA (American Psychiatric Association). In Greek and Hellenistic culture, however, homosexuality was regarded as natural and normal for centuries! Today, none of these behaviors are accepted as perversions and pathology by modern psychiatry as defined in DSM-5; even BDSM (Bondage-Domination-Sadomasochism) is, today, in debate, whether it should be classified as a paraphilia in DSM [17-23]. Moser and Sayin (from 2011 to 2013) disputed the HDSI (Hypersexual Disorder Screening Inventory) criteria and criticized the definition of "Hypersexual Disorder" which was about to be added into DSM-5 by APA in 2013 [17-20,24-27].

Thus, what should we refer and accept as the universal reference system, when we discuss about "the normal sexual behavior"? Institutionalized religions and "Holly Books" are far away from constructing such an ethical system; it has also been shown, repeated times, that they contradict with most of the findings of the rational mind and modern science. Besides, "Holly Books" are galaxies away for being accepted as the "true quotations or words" of a sacred, anthropomorphic, Omni-potent, male "Father-God" or "Sun-God", who created the universe, earth and "the perfect human beings" in 6 days and rested on the $7^{\text {th }}$ day and who put millions of sanctions, compulsory duties and punishments (eventually Heaven and Hell) on humans and expected respect, submission, belief, and strict obedience afterwards, honored as being the true reflection of "Universal Love", whatever it is in this wild capitalist global jungle! Thus, no religious reference can be taken as the basic ethics of determining the normal sexual behavior; if taken, then that is pseudo-science or junk-science. Defining "the normal" using a bell curve and standard deviations seems to be pointless, because the "average behavior in the bell curve" also changes depending upon the culture, era, society, century, country; thus, the bell curve's normal is very subjective and swinging to both sides. So, we have to make very objective, rational and scientific definitions of such flexible conceptions, after performing many surveys, to establish some rigid conclusions, when we discuss about "the normal and the deviant behavior"!

As described above, taken the fact that "the definitions of the normal in sexual behavior changes", we have to re-assess the terms like fantasy, sexual object (SO), sexual pleasure object (SEPO) (different than sex object), sexual variations, soft BDSM, hard BDSM, expanded sexual response (ESR), expanded orgasm (EO), status orgasmus, never ending-limitless orgasms (LO), hypersexuality (HPS), sex addiction (SxAdd), and nymphomania. They should be discussed and re-assessed according to the accumulating data from different sources, researches, surveys and cultures.

\section{Sex object and sexual pleasure object: The fetishist, the voyeurism and the exhibitionist inside}

Sex Object (SO) is a fetish object or a human being or an event or a thing that induces sexual arousal at different degrees in each person. Human beings are aroused seeing or feeling or observing different sex objects at different levels. Some particular people, such as actors and actresses, may become sex objects. Some clothing, dress or things in daily life may become sex objects, such as lingerie, high heels, masculine men, beautiful female face, leather clothing, tattoos, piercing etc. However, these contribute to the development of sexual arousal, and they are not the only targets of sexual arousal and pleasure, eventually orgasm. In pathological fetishism, that particular object is the only arousal-pleasureorgasm target of the fetishist individual, he/she cannot reach climax without the existence of that object (lingerie, leather, PVC or vinyl cloths) preferring this fetish object to sexual interaction with a human being or regular intercourse. He/she is obsessed with the object and she/he, obsessive compulsively, repeats this sexual ritual with the fetish object(s). However, fetish objects are, today everywhere, from fashion to every portion of daily life and some people find them attractive. In the sexual minds of most of the people, they increase sexual arousal and attraction, but they do not become the only satisfaction objects. A fetish object, which is only attractive to a person in the beginning, may become, one day, a hot and powerful sexual attraction or "orgasm" object. So where shall we put the limits of being normal and pathological of that particular fetish object(s) and whom shall we call fetishist? We have to make clear cut definitions for such a pathology $[3,4,7,24,25]$.

Sexual Pleasure Object (SEPO) is a learned sexually arousing and attractive sexual object or an act or a person or an entity, which contains "human dynamic psychological assessment"; "dynamic psychology" of a human being who creates the SEPO. SEPO is different than sex object, but more arousing for that particular person. For instance, a beautiful female face can be a sex object; it may be arousing; "an orgasmic female face" is a SEPO, which contains an action and dynamic features in it. SEPO, however, is more arousing for most of the people. A man or actress can be a pleasure object; however, some actors or actresses may become SEPOs. As an example, Marilyn Monroe (MM) had a beautiful face (a sex object), however, most of her face pictures were found as very sexy and attractive compared with many other beautiful faces, because most of the latest pictures of her face had the expression of getting pleasure or having an orgasm (SEPO). Unconsciously, people who were the fans of MM were actually affected by her facial expression of a beautiful woman having sex, getting pleasure or reaching the climax (Psycho-dynamic factor). Similarly, there are many actors who are not that handsome, but the dynamism of that character, facial expression, and the roles he plays makes him a SEPO, e.g. Jack Nicholson. Thus, in SEPO, our dynamic psychological assessment is involved, and makes the sex object more arousing and attractive $[1-4,7,24,25]$. 
When we redefine exhibitionism, voyeurism, fetishism we have to stress the clear-cut differences in the pathological context. Exhibitionism and voyeurism are normal, actually, in daily life; most of the people have those inclinations; otherwise how would it be possible to explain the growth of porn and hard-core film industry? Sex therapists, today, are suggesting some of their patients to watch soft core erotic movies and porno. People like to watch others making love, and they love to imitate them; some women are inclined to show some parts of their bodies using provocative dresses and lingerie; some women are mild exhibitionists. Most people use fetish objects during daily lives, such as, tattoos, piercings, leather, PVC, rubber etc. Can we diagnose them as fetishists and a mental disorder? (Table 1) [26,27].

Table1: Fetishism, exhibitionism and voyeurism as pathology and non-pathology.

\begin{tabular}{|c|c|}
\hline Fetishism-Acceptable-Not Pathology & Fetishism-Pathology \\
\hline Practiced as a part of fantasy and sexual variation. & Obsessive-Compulsive component \\
\hline Does not give harm to the self and others & Uncontrollable \\
\hline Controllable and not an obsession. & Creates inner conflicts and neurosis (depression, anxiety etc.) \\
\hline Can get satisfaction from normal sexual activity, fetish is a SEPO & Cannot get satisfaction and orgasm otherwise \\
\hline Does not create inner conflicts in the psyche & Aggressive, gives harm to others' psychology or physiology \\
\hline There may be or may be NOT accompanying other psychiatric disorders. & Gives harm to his/her own psychology \\
\hline \multirow[t]{2}{*}{ Mild fetishism } & Generally, occurs with other psychiatric disorders \\
\hline & Severe fetishism \\
\hline Exhibitionism-Acceptable-Not Pathology & Exhibitionism-Pathology \\
\hline $\begin{array}{l}\text { Part of daily activity and not a center of sexual foreplay (particularly for } \\
\text { women) }\end{array}$ & Obsessive-Compulsive component \\
\hline Not obsession and controllable & Uncontrollable \\
\hline Does not contain the elements of domination and sadism. & Creates inner conflicts and neurosis (depression, anxiety etc.) \\
\hline Performed on people who may give consent. & Cannot get satisfaction and orgasm otherwise \\
\hline Not a part of a dominant-aggressive behavior & $\begin{array}{l}\text { Aggressive, gives harm to others' psychology or physiology; no empa- } \\
\text { thy, uses people }\end{array}$ \\
\hline Does not give harm to her psychology. & Gives harm to his/her own psychology \\
\hline May give some harm to the subject's psychology (being provocative) & Has a sadistic and dominance factor. \\
\hline Can get pleasure and attain orgasm during normal other sexual activities. & Performed on people who are unnoticed and giving no consent. \\
\hline There may be or may be NOT accompanying other psychiatric disorders. & A part of dominant-aggressive behavior \\
\hline \multirow[t]{3}{*}{ Mild exhibitionism } & Performed generally to shock sexual subject, and showing genitals \\
\hline & Generally, occurs with other psychiatric disorders \\
\hline & Severe exhibitionism \\
\hline Voyeurism-Acceptable-Not Pathology & Voyeurism-Pathology \\
\hline Does not have obsessive compulsive component & Obsessive-Compulsive component \\
\hline Controllable & Uncontrollable \\
\hline Does not create inner conflict of the self & Creates inner conflicts and neurosis (depression, anxiety etc.) \\
\hline $\begin{array}{c}\text { Performed as small part of sexual variation (watching hard core movies or live } \\
\text { shows) }\end{array}$ & Cannot get satisfaction and orgasm otherwise \\
\hline Not aggressive & $\begin{array}{l}\text { Aggressive, gives harm to others' psychology or physiology; no empa- } \\
\text { thy, uses people }\end{array}$ \\
\hline $\begin{array}{l}\text { Can get satisfaction by means of other activities and regular sexual inter- } \\
\text { course or other; watching or voyeurism is a SEPO. }\end{array}$ & Gives harm to his/her own psychology \\
\hline There may be or may be NOT accompanying other psychiatric disorders. & Performed secretly on unnoticing people with no consent \\
\hline \multirow[t]{2}{*}{ Mild or moderate voyeurism. } & Generally, occurs with other psychiatric disorders. \\
\hline & Severe Voyeurism \\
\hline
\end{tabular}




\section{Fantasy and sexual variations: Beyond the normal and paraphilia}

Imagining sexual fantasies is a quite normal behavior. Most of the time, people have sexual fantasies during the intercourse with the partner, during masturbation or during being aroused. Generally, a fantasy accompanies masturbation, which is another normal and healthy sexual behavior. Today sex therapy begins to teach masturbation to the patients. One hundred and twenty years ago, though, fantasy and masturbation were regarded a pathology and mental illness by medical authorities. It was Havelock Ellis, Sigmund Freud, Carl Gustav Jung, Wilhelm Reich who claimed that every women and man had fantasies and they masturbated since childhood [1,3,4,25,28-30]. Fantasy and masturbation were accepted as perversions at the turn of 20th Century, called as "Onanism".

During the course of a normal life a normal man or women will have from 7000 to 15000 (or more) masturbation sessions until the age of 50; he/she will have more fantasies than these figures, and today masturbation and fantasies are accepted as natural and healthy [7]. Catholicism and Judaism banned masturbation totally for centuries. For most of the institutionalized religions normal sexual activity was defined as: "Having intercourse to produce babies, particularly in the missionary position"; any behavior related with sex that did not have the purpose of reproduction, was glanced as "perversion" and "sexual deviation". If sexual activity would consist of just intercourse, it would become very dull after a while; besides it is a reported fact that only $30-34 \%$ of all women can attain orgasm through "only" intercourse; this figure is $17-20 \%$ in Turkey $[3,4,31,32]$. Fantasies, masturbation, oral sex, anal sex, orgasm using therapy toys (sex toys) etc. are still regarded as "perversions" in many cultures and countries today; however, they are the main methods of modern sex therapy currently and they make the sexual lives of many people more colorful and pleasurable. The anorgasmia frequency among women is 5 to $14 \%$ globally [1-7,31-34]; coitalvaginal anorgasmia (lack of vaginal orgasms, but not clitoral orgasms) frequency is $65-70 \%$ in USA and Europe [1-7,31-34] and $82-85 \%$ in Turkey $[1-7,25]$. Most of the time, sexual fantasies do not become real. Particularly women fantasize about some of the impossible events; women are more imagination and fantasy oriented, while men are image oriented during masturbation. Most of the women do not realize what they have fantasized during masturbation; fantasy gives a kind of freedom and limitlessness to their sexual minds and to develop their sexual brains and SQ. Along with fantasies, sexual variations are also important in sexual lives of couples today. Sexual games, fantasy role play, taking another partner to the relationship and various forms of sexual variations are being practiced by many people more frequently than before. One of the reasons of seeking variations is the Coolidge Effect. The Coolidge effect is a biological and psychological phenomenon seen in animals and humans, whereby males exhibit renewed sexual interest whenever a new female is introduced to have sex with, even after cessation of sex with the prior partner, while there are still available different sexual partners and choices [7,35,36] The effect is also seen among females with regard to their mates $[7,36]$.

The Coolidge effect can be attributed to an increase in sexual responsiveness, and a decrease in the refractory period [36-39]. The evolutionary outcome of this phenomenon is that a male can fertilize multiple females and can spread the genes to many other females of the same species [39]. Coolidge effect was detected in many different species and lately in Homo sapiens as well [7,40,41]. Male or female partners may become dull and people may become desensitized to each other. Sometimes introducing new different partners to the relationship or swinging partners may be practiced as a variation. After the Kinsey Reports came out in the early 1950s, findings suggested that historically and cross-culturally, extramarital sex has been a matter of regulation more than sex before marriage [42]. The Kinsey Reports found that around half of men and a quarter of women studied had committed adultery [43]. The Janus Report on Sexual Behavior in America also reported that one third of married men and a quarter of women have had an extramarital affair [44]. Actually nearly $40-60 \%$ of the male's cheat on women during marriages and while living together $[3,4]$, similarly $25-30 \%$ of women cheat on men in marriages or love relationships (cheating the partners and spouses combined together). Sometimes different sexual variations, partner swapping, group sex, different fantasy role play, finding novel partners into the relationship may save most of the marriages, of which sexual satisfaction level has dropped during long years due to monotony. So, none of these behaviors can be accepted as an anomaly, pathology or perversion.

\section{Sexual mind and sexual brain}

Sexual Mind and Sexual Brain are two new concepts [7]. Sexual Mind is the "sexual psyche" which determines the sexual behavior and sexual preferences, sexual inclinations and arousal, fantasies, sexual variations, orgasmic patterns and other diversities, whether these diversities are accepted pathological or not by the norms of the society. Sexual Brain is the neurological and biological part of the Sexual Mind. Intelligence Quotient (IQ) and Emotional Quotient (EQ) are two dimensions of sexual mind; both of them can be measured and quantified [4,7]. The main components of Emotional Intelligence (EQ) are [7,45-48]:

A. Self-Awareness

B. Self-Regulation and Self-Control

C. Motivation

D. Empathy

E. Social Intelligence

In the development of Sexual Mind, EQ may even be more important than IQ. Sexual Intelligence (SQ) can also be measured (we are working on more objective psychometric scales of EQ and SQ). Sexual Mind and SQ can be learned and developed; life and 
sexual experience is one of the main factors in the development of SQ. Sexual intelligence can be learned and developed while IQ is genetically inherited and innate. Sexual intelligence determines the level of sexual interactions with the partners. Increased Table 2: Intelligence types which interact with sexual behavior. libido, sexual variations, high fantasy levels, imaginativeness, unconventional recreational sex, creativity, fantasy role playing, playing sexual games are some of the components of sexual intelligence (SQ) [7] (Table 2).

\begin{tabular}{|c|c|c|}
\hline Intelligence Quotient (IQ) & Emotional Intelligence (EQ) & Sexual Intelligence (SQ) \\
\hline $\begin{array}{l}\text { Deals with the analysis and synthesis capacities of } \\
\text { the frontal cortex, such as verbal ability, mathemat- } \\
\text { ical or geometrical ability, memory and recalling, } \\
\text { arithmetical ability, high affinity and capability to } \\
\text { play with numbers or codes. }\end{array}$ & $\begin{array}{l}\text { Deals with the self-control, self-awareness, mo- } \\
\text { tivation, empathy, social interactions and social } \\
\text { intelligence. EQ enables one person to interact } \\
\text { with other people and be successful in social } \\
\text { life. Also have the components of adaptation to a } \\
\text { group, society and people. }\end{array}$ & $\begin{array}{l}\text { Contains many motives of IQ and EQ. Also } \\
\text { contains the elements learned and experi- } \\
\text { enced through life. Giving and getting more } \\
\text { pleasure is the main parameter. Fantasy, } \\
\text { variations, different and unconventional } \\
\text { attitudes toward the partner, Creative- } \\
\text { ness, creating new SEPOs are some of the } \\
\text { parameters. }\end{array}$ \\
\hline Can be measured. There are IQ tests. & $\begin{array}{l}\text { Can be measured. During the last three decades } \\
\text { some novel multi-dimensional tests have been } \\
\text { developed. }\end{array}$ & $\begin{array}{l}\text { There are no psychometric tests available } \\
\text { yet. }\end{array}$ \\
\hline Innate, cannot be developed & Can be developed to some degree. & Can be learned and developed \\
\hline $\begin{array}{l}\text { High IQ: In the case of genius men who can solve } \\
\text { very complex problems, remembers a lot of details, } \\
\text { multiplies 4-digit numbers in seconds faster than } \\
\text { calculators, or learn a language in short period of } \\
\text { time. }\end{array}$ & $\begin{array}{l}\text { High EQ: Near to high IQ some people are very } \\
\text { successful in social life and they can be very effec- } \\
\text { tive in solving business or social problems. They } \\
\text { have a good impact and influence on people. They } \\
\text { can be leaders. }\end{array}$ & $\begin{array}{l}\text { High SQ: They have a very good at adap- } \\
\text { tation in sexual interactions and sexual } \\
\text { encounters, for instance an ESR woman } \\
\text { can have limitless orgasms and give more } \\
\text { pleasure to man. They are sexually very ex- } \\
\text { perienced. They can adapt easily to different } \\
\text { conditions; they have a broad imagination; } \\
\text { various fantasy level and they like to per- } \\
\text { form many sexual variations. }\end{array}$ \\
\hline High IQ is introvert most of the time. & High EQ is very extrovert. & High SQ can be both ambivert and extrovert \\
\hline
\end{tabular}

\section{Paraphilia: a unified definition?}

To define a sexual behavior as pathology, there should be some certain rigid rules and solid definitions. Diagnosing someone as a pervert or having paraphilias is an ethical issue. Is a woman with hyperactive sexual lifestyle, a paraphilic? It should not be so easy to label people with mental disorders, as APA tried to do for DSM-5, by proposing a "Hypersexual Disorder Proposal" in 2013, following HDSI Criteria described in the articles of Martin P Kafka [49]. HDSI criteria and "Hypersexual Disorder Proposal" was refuted by many researchers and academicians [17-25,50-52].

As we have given in the case of exhibitionism, voyeurism and fetishism, we can propose similar criteria for a universal definition of paraphilia:

1. The sexual arousal and orgasm should only be directed to a non-human object or to only a body part of a human-object (e.g. high heel or lingerie fetishism, podophilia, morphophilia, partialism) or a partially handicapped or totally handicapped person (e.g. Gerontophilia, Abasi-ophilia, Acrotomophilia, Apotemnophilia) or a non-living human being (Necrophilia).

2. The person should not get pleasure, arousal, satisfaction and orgasm other than this non-human object or the body part of a human-object or others above (at 1) with which he/she is obsessed.

3. Sexual pleasure, arousal, satisfaction and orgasm should be directed to a non-human live object or animal (e.g. Zoophilia), under-developed human being who has not completed the physiological and psychological maturity to become an adult (e.g. pedophilia, infantilism), a non-consenting individual (e.g. pathological exhibitionism, Peodeiktophilia, Salirophilia, Frotteurism, Molestation, Rape).

4. Sexual pleasure, arousal, satisfaction and orgasm should be attained by extreme mental humiliation, physical pain, mutilation, injury inflicted by others or by the self. The person should be aroused and should attain orgasm through extreme bondage, domination and other forms of sadomasochistic behavior. The sexual activity should give physical harm to the self. The person should not get pleasure or satisfaction with other regular forms of sexual behavior, such as intercourse, making love etc. other than this obsession (e.g. severe masochism). This should be differentiated from variation soft BDSM.

5. Sexual pleasure, arousal, satisfaction and orgasms should be attained by inducing or inflicting extreme mental domination or humiliation, psychological molestation, mobbing, domination, bondage, physical pain, mutilation or injury to others (men or women). The sexual activity should give physical harm to others. The person should not get pleasure or satisfaction with other regular forms of sexual behavior, such as intercourse, making love etc. other than performing this obsession (e.g. severe sadism). This should be differentiated from variation-soft-BDSM.

6. It should be uncontrollable and/or preferred behavior, preferred to couple mutual sexual activity. 
7. It should be practiced repeatedly and obsessive compulsively, preferred to couple mutual sexual activity.

8. It should induce psychological harm to others and/or to the self. Or it should be a manifestation of a mental disorder.

9. It should not be replaced with other sexual variations, SEPOs, couple mutual sexual activity and other forms of sexual behavior to attain pleasure, satisfaction and orgasm.

10. It should interfere (very negatively) with the social life, school \& education life, business life and social bonding. It should prevent consistent and loving relationship or coupling with partners.

Numbers 6-10 should be the compulsory conditions for the diagnosis of paraphilia, because they already reflect a form of mental and psychological disorder and they contain the elements of pathology. 1-5 are the particular types of the forms of paraphilia. Using such a universal definition of paraphilia a psychometric scale can easily be designed to fit different forms of deviant behavior. This psychometric scale will have quantification and a score, which can determine the severity of the paraphilia.

\section{Soft BDSM and hard BDSM: The aggressive amygdala and the pleasure}

A 2011-BDSM book series entitled as "Fifty Shades of Gray" sold more than 150 million copies (2015 estimation) in four years. In many European countries, such as England and Norway, it sold more than the Bible during those years. It is a rumor that more than $60-65 \%$ of the readers were female. This means that an important portion of global people read "Fifty Shades of Gray", which contained scenes of, not only variation BDSM, but also hard core, severe BDSM as a sexual fantasy book and influenced by the book trilogy.

A new Kinsey Report among American people revealed that $22 \%$ of men and $12 \%$ of women had BDSM fantasies, while most of them had at least one BDSM experience [33]. According to Janus Report (1993) 14\% of males and 11\% of females practiced BDSM at least one time in their lives [44]. Our reports on women in Turkey (Kadınca Report, 1993; Hülya Report, 2003; İstanbul Report, 20132019, continuing) revealed that $9-14 \%$ of Turkish women had BDSM fantasies $[3,25]$. In a recent survey on sexual deviance among 15937 people, $9 \%$ of the correspondents claimed to be sadist, $22 \%$ said they were masochists, and $22 \%$ accepted they swung both sides, while 54\% were neither of them [53]. So, in different cultures there is substantial frequency of people who have the fantasies of BDSM as a variation, some of this population practices BDSM. The fantasy group is around $15-20 \%$ and BDSM practitioner group is approximately $8-12 \%$ according to different surveys and reports $[3,4,7,24,25]$.

Thus, we have a huge population of people who may have mild BDSM fantasies and practice mild BDSM as a variation to increase arousal and to enhance orgasms. Should we call all of them as perverts or paraphilic? If we do not accept many kinds of sexual variations as paraphilia, then some mild BDSM practices should be considered as fantasy role play, sexual games and sexual variations.
In a recent 2013-study comparing 904 BDSM practitioners and 434 normal people 4 personality tests were applied: Big Five personality dimensions tests, Attachment styles test, Rejection sensitivity test, Subjective well-being test. The result of the study proved that the scores of the BDSM practitioners were not that pathological and extreme compared with the controls [54] BDSM practitioners were found as: "The results mostly suggest favorable psychological characteristics of BDSM practitioners compared with the control group; BDSM practitioners were less neurotic, more extraverted, more open to new experiences, more conscientious, less rejection sensitive, had higher subjective well-being, yet were less agreeable. Comparing the four groups, if differences were observed, BDSM scores were generally more favorably for those with a dominant than a submissive role, with least favorable scores for controls. It was concluded that BDSM may be thought of as a recreational leisure, rather than the expression of psychopathological processes. "

The neuroscience of soft BDSM and hard BDSM are still under investigation. As known amygdala is responsible of fear reactions, aggressiveness, anxiety, various emotions and sexual arousal along with the information process ability of hippocampus [3,25,55-57]. It is proposed that BDSM practices (or even only the fantasies of BDSM), may increase the release of some neurotransmitters such as endorphin, norepinephrine (NE), dopamine (DA) and oxytocin (OXT) $[4,7,25,58]$. Particularly if the conditioned learning and reflex mechanisms and neural circuitry of pleasure \& reward, starting from Ventral Tegmental Area (VTA) via N. Accumbens (NA) through prefrontal cortex, are organized and activated such that they release excessive amounts of DA in response to painful and fearful BDSM stimuli; then this learned phenomenon may alter the synaptic plasticity in various areas of the brain such as amygdala, hippocampus, prefrontal cortex, frontal cortex, anterior cingulate cortex, insula, VTA, NA, ventral pallidum and raphe nuclei [55, 56 ]. Novel variation stimuli of soft BDSM (or even hard BDSM) or the stimuli of SEPOs may act as an innate central nervous stimulant at the pleasure centers of the brain, just like in the case of cocaine and methamphetamine administration [55,56,59].

The anterior cingulate and insula are activated at orgasms, but they can also be activated by painful stimuli [60-62]. There is a possibility that pain, and orgasm may be using similar or the same spinothalamic pathways, a neurophysiological mechanism which can explain why some women and men enjoy mild pain and pleasure/orgasm together in BDSM sessions. Also, it is shown that female orgasm is analgesic [63-66], probably due to the release of oxytocin, which has also analgesic effects, and endogenous opioids. This can also explain how mild pain and orgasmic pleasure can be interchangeable with each other. Most of the time, however, BDSM behavior is very much correlated with childhood experiences; namely, it is a neurological and psychological learned and conditioned behavior which takes its roots from striking childhood events, such as child games among children, child punishment in the family or in the school, child abuse, child molestation and rape. In the case of a patient of Carl Gustav Jung and Sigmund Freud, a Jewish hysteria-schizophrenia case (true story-Sabina Spielrein) 
where Sabina could only attain orgasm by means of being tied and spanked or beaten; because she used to be punished by her father, stripped stark naked when she was a child, thus punishment became a SEPO for her (See the movie: "A Dangerous Method" directed by David Croningberg, 2011). A similar true story was also shown in the famous 2013-film "Nympho-maniac" (see the movie: "Nymphomaniac" directed by Lars von Trier, 2013). In this movie also the heroine Joe suffers from sex addiction and BDSM fantasies, due to her childhood experiences; she can, most of the time, achieve orgasm when she is tied up and punished, or flogged by a powerful whip.

Table 3: Different forms of BDSM Behavior to elucidate

mild-variation-BDSM and pathological-severe-BDSM.

\begin{tabular}{|c|c|c|}
\hline A-Mild BDSM as a SEPO and Variation & $\begin{array}{l}\text { B-Intermediate Mild BDSM as a SEPO and } \\
\text { Variation }\end{array}$ & C-Severe BDSM as a Paraphilia \\
\hline $\begin{array}{c}\text { Practices } \\
\text { Fantasies of BDSM }\end{array}$ & $\begin{array}{c}\text { Practices } \\
\text { Fantasies of more severe and hard BDSM }\end{array}$ & $\begin{array}{l}\text { Practices } \\
\text { Hard bondage }\end{array}$ \\
\hline Blindfolding & Blindfolding-Bondage-Gaging & Hard BDSM practices \\
\hline Tying, immobilizing & Spanking & Severe humiliation \\
\hline Fantasy role play of power games & Verbal BDSM and telling fantasies & $\begin{array}{c}\text { Using all kind of BDSM toys (blindfolds, } \\
\text { chains, inflatable gags, tight ropes, } \\
\text { hand cuff, restraints) }\end{array}$ \\
\hline Soft Bondage & Reading and watching various BDSM films & Whipping and inflicting pain \\
\hline Reading BDSM & More practice of BDSM than fantasy & Using needles \\
\hline Verbal BDSM & BDSM fantasy role play and games & $\begin{array}{l}\text { Using electro-shock devices and inflict- } \\
\text { ing considerable pain }\end{array}$ \\
\hline \multirow[t]{3}{*}{ Mild spanking and punishing } & More real power games & Severe master-slave relationship \\
\hline & Punishment games & \\
\hline & Mild Slave-master games & \\
\hline No pain infliction & No pain infliction, or mild pain & There is pain infliction \\
\hline No injuries & No injuries & There may be welts and injuries \\
\hline There are Safe words & There are Safe words & There may be or may not be Safe words \\
\hline No severe tying or severe welts & No severe tying or severe welts & There is physical harm \\
\hline No physical harm & No physical harm & $\begin{array}{l}\text { There may be or may not be psycholog- } \\
\text { ical harm }\end{array}$ \\
\hline $\begin{array}{c}\text { No psychological harm, only as a variation to increase } \\
\text { arousal }\end{array}$ & $\begin{array}{c}\text { No psychological harm, only as a variation to increase } \\
\text { arousal }\end{array}$ & Most of the time uncontrollable \\
\hline No obsessive-compulsive elements & No obsessive-compulsive elements & $\begin{array}{l}\text { Most of the time there is obsessive } \\
\text { compulsive elements }\end{array}$ \\
\hline $\begin{array}{c}\text { Can get pleasure and attain orgasm by means of many } \\
\text { other sexual acts, e.g. sexual intercourse. }\end{array}$ & $\begin{array}{l}\text { Can get pleasure and attain orgasm by means of many } \\
\text { other sexual acts, e.g. sexual intercourse. }\end{array}$ & $\begin{array}{l}\text { Cannot get pleasure from many other } \\
\text { sexual activities alone without BDSM }\end{array}$ \\
\hline Does not induce inner conflicts. & Does not induce inner conflicts. & May induce inner conflicts \\
\hline SEPO level & SEPO level & $\begin{array}{c}\text { Not SEPO or fantasy level, but hard } \\
\text { core BDSM. }\end{array}$ \\
\hline
\end{tabular}

In Table 3, the behaviors at different levels of BDSM are depicted. We need to make this distinction because BDSM behavior is not a single unity; it may be split into different behaviors or fantasies of BDSM. Some people perform sometimes mild BDSM as a variation and do not pass to more severe practices; some people perform a little bit harder practices (Intermediate Mild BDSM) and stay there as a sexual variation. In Table $3, \mathrm{~A}$ and $\mathrm{B}$ cannot be accepted as a paraphilia, but they are SEPOs and sexual variations. However, in the medical literature when BDSM is mentioned everyone thinks and remembers of hard-core bondage, hard BDSM pornography, whipping, caning, flogging, inflicted pain by all means, such as inserting needles or giving electro-shocks etc. In A and B, such practices do not exist. 
Table 4: A Model for the levels of masochistic behavior. Masochistic Level Scale. Up to level 10 should be considered as a variation, not a paraphilia.

\section{1-Sexual preference}

A) Submissive Heterosexual B) Submissive bisexual C) Submissive lesbian (plays Female role) D) Submissive lesbian (plays male role) D) Submissive (playing both male/Female roles) E) Submissive cross-dresser Women F) Submissive TV G) Submissive Transsexual

\section{2-General role}

A) Always submissive B) Mostly submissive, but changing roles C) Sometimes submissive, sometimes dominant (equal frequencies 3-Did you experience abuse, molestation or rape during your childhood (3-13 years old)?

A- No None. B-Mild abuse, molestation C-Moderate abuse or molestation D-Severe sexual abuse E- Rape F-Punishment G- Punishment which became a sexual pleasure object when you were adult H-Moderate BDSM abuse I-Severe BDSM abuse J-Torture and severe punishment

4-Question about piercings and tattoos

5-Questions about self-mutilation

\begin{tabular}{|c|c|c|c|c|}
\hline \multicolumn{5}{|c|}{ Measuring the Level and The Intensity of BDSM Activity and Behavior-Submissive Scale } \\
\hline Level & Definition & Examples of Behavior & $\begin{array}{l}\text { No } \\
\text { org }\end{array}$ & $\begin{array}{l}\text { With } \\
\text { org }\end{array}$ \\
\hline $\begin{array}{l}1 \\
\text { V. Mild } \\
\text { A }\end{array}$ & $\begin{array}{l}\text { Very mild level BDSM. } \\
\text { (fantasy level A) No BDSM Practice in } \\
\text { real life }\end{array}$ & $\begin{array}{l}\text { Likes being controlled, submission; fantasies of control, these are at } \\
\text { the complimentary level. No orgasm with those fantasies. No Orgasm }\end{array}$ & & \\
\hline $\begin{array}{c}2 \\
\text { Mild } \\
\text { B }\end{array}$ & $\begin{array}{l}\text { Mild Levels of BDSM } \\
\text { (fantasy level B) No BDSM Practice in } \\
\text { real life }\end{array}$ & $\begin{array}{c}\text { In masturbation fantasies mild BDSM enhances sexual pleasure and } \\
\text { orgasm. Fantasies of humiliation, being tied up, blindfolded as a part } \\
\text { of sexual activity and variation. These fantasies facilitate to reach } \\
\text { orgasm. Orgasm }\end{array}$ & & \\
\hline $\begin{array}{l}3 \\
\text { Mild } \\
\text { C }\end{array}$ & $\begin{array}{l}\text { Mild Levels of BDSM } \\
\text { (fantasy level C) No BDSM Practice in } \\
\text { real life }\end{array}$ & $\begin{array}{c}\text { Moderate BDSM but not severe BDSM fantasy-activity (imagining, } \\
\text { watching arouses, enhances sexual pleasure) } \\
\text { But No Orgasm }\end{array}$ & & \\
\hline $\begin{array}{l}4 \\
\text { Mild } \\
D\end{array}$ & $\begin{array}{l}\text { Mild Levels of BDSM } \\
\text { (Fantasy level D) No BDSM Practice in } \\
\text { real life }\end{array}$ & $\begin{array}{l}\text { Moderate or severe BDSM activity fantasy, watching BDSM films } \\
\text { arouse, enhances sexual pleasure. BDSM activity fantasy or watching } \\
\text { leads to Orgasm. }\end{array}$ & & \\
\hline $\begin{array}{l}5 \\
\text { Beg. } \\
\text { A }\end{array}$ & $\begin{array}{l}\text { Beginner BDSM Level-A } \\
\text { Practiced in real life at least } 2 \text { times in } \\
\text { the past and enjoyment is uncertain }\end{array}$ & $\begin{array}{l}\text { Some soft BDSM activity as a variation only. No hard BDSM. } \\
\text { Fantasies of (1) realized. Enhances arousal and sexual excitement, } \\
\text { enhances sexual pleasure. No orgasm with this activity. No Orgasm. }\end{array}$ & & \\
\hline $\begin{array}{c}6 \\
\text { Beg. } \\
\text { B }\end{array}$ & $\begin{array}{l}\text { Beginner BDSM Level-B } \\
\text { Practiced in real life at least } 2 \text { times in } \\
\text { the past and enjoyed. }\end{array}$ & $\begin{array}{l}\text { In practice tied up, experienced soft bondage; blindfolded; very } \\
\text { soft BDSM practice as a part of fantasy and variation. This activity } \\
\text { enhances arousal, excitement, sexual pleasure. The activity facilitates } \\
\text { Orgasm and/or enhances the intensity of Orgasm. Orgasm. }\end{array}$ & & \\
\hline $\begin{array}{l}7 \\
\text { Beg. } \\
\text { C }\end{array}$ & $\begin{array}{l}\text { Beginner BDSM Level-C } \\
\text { Practiced in real life at least } 2-5 \text { times in } \\
\text { the past and enjoyed. }\end{array}$ & $\begin{array}{l}\text { Having the role of a submissive (but not slave); taking orders, being } \\
\text { played with, tied up, being forced to be in different sexual activities } \\
\text { (such as spanking, mild pain, nipple clamps etc.) No Severe Pain or } \\
\text { impact play or other methods of pain. BDSM practice just for mind. } \\
\text { Enhances pleasure, arousal and orgasm. With Orgasm. }\end{array}$ & & \\
\hline $\begin{array}{c}8 \\
\text { Beg. } \\
\text { D }\end{array}$ & $\begin{array}{l}\text { Beginner BDSM Level-D } \\
\text { Practiced in real life at least } 2-5 \text { times in } \\
\text { the past and enjoyed. } \\
\text { Safe word }\end{array}$ & $\begin{array}{c}\text { Having the submissive role as a slave, in a slave-master role playing; } \\
\text { but as a variation. Being controlled, played with, tied up; controlled } \\
\text { orgasm or forced orgasm; being forced to be in different sexual activ- } \\
\text { ities (such as spanking, mild pain, nipple clamps etc.) No Severe Pain } \\
\text { or IMPACT PLAY or other methods of pain. Just a sexual slave-master } \\
\text { game. BDSM practice and being submissive and slave gives pleasure; } \\
\text { arousal; enhances orgasm. With orgasm }\end{array}$ & & \\
\hline $\begin{array}{c}9 \\
\text { Intm } \\
\text { A }\end{array}$ & $\begin{array}{l}\text { Intermediate BDSM Level-A } \\
\text { Practiced in real life. } \\
\text { BDSM activity frequency } 1-10 \% \text { at } \\
\text { much of all sexual activities/ Safe word }\end{array}$ & $\begin{array}{l}\text { Having the submissive role as a slave in a master-slave role playing. } \\
\text { Still a variation and just a part of the sexual activity. Enjoys also } \\
\text { other non-BDSM forms of sexual activity. Being controlled, played } \\
\text { with, tied up; controlled orgasm or forced orgasm; being forced to } \\
\text { take role in different sexual activities (such as Impact play, mild pain, } \\
\text { nipple clamps etc.) no severe pain or impact play or other methods } \\
\text { of pain. Just a sexual slave-master game. With Orgasm / Affiliation } \\
\text { to BDSM: } 1-10 \% \text { of all sexual activities / Affiliation to non-BDSM } \\
\text { activities: } 90-99 \% \text { / BDSM is not a must, but accessory / Safe word } \\
\text { is considered. }\end{array}$ & & \\
\hline
\end{tabular}




\begin{tabular}{|c|c|c|}
\hline $\begin{array}{c}10 \\
\text { Intm }\end{array}$ & $\begin{array}{l}\text { Intermediate BDSM Level-B } \\
\text { Practiced in real life. }\end{array}$ & $\begin{array}{l}\text { Having the submissive role as a slave in a master-slave role playing. } \\
\text { Further than just a variation. Enjoys also other non-BDSM forms of } \\
\text { sexual activity. Being controlled, played with, tied up; controlled or- } \\
\text { gasm or forced orgasm; being forced to take role in different sexual } \\
\text { activities (such as Impact play; mild pain; nipple clamps; vibe play; } \\
\text { moderate bondage; being bitten; genital play and humiliation; breast } \\
\text { or buttock impact play; being locked; handcuffed, chained etc.) Mod- } \\
\text { erate Pain with impact play. no severe pain or impact play or other } \\
\text { methods of severe pain. More than a role play: Slave-master relation- } \\
\text { ship; BDSM practice and being submissive and slave give pleasure; } \\
\text { arousal; enhances orgasm. With Orgasm / Affiliation to BDSM :10- } \\
\text { 25\% / Affiliation to non-BDSM activities: } 75-90 \% \text { / BDSM is one of } \\
\text { the most arousing activities / Safe word }\end{array}$ \\
\hline B SAFE WORD & $\begin{array}{l}\text { BDSM activity frequency } 10-25 \% \text { of all } \\
\text { sexual activities / Safe word }\end{array}$ & $\begin{array}{l}\text { locked; handcuffed, chained etc.) Moderate pain with impact play. no } \\
\text { severe pain or impact play or other methods of severe pain. More than } \\
\text { a role play: Slave-master relationship; BDSM practice and being sub- } \\
\text { missive and slave give pleasure; arousal; enhances orgasm. With Or- } \\
\text { gasm / Affiliation to BDSM :10-25\% / Affiliation to non-BDSM activi- } \\
\text { ties: } 75-90 \% \text { / BDSM is one of the most arousing activities / Safe word }\end{array}$ \\
\hline $\begin{array}{c}11 \\
\text { Intm } \\
\text { C }\end{array}$ & $\begin{array}{l}\text { Intermediate BDSM Level-C } \\
\text { Practiced in real life. } \\
\text { BDSM activity frequency at least } 25- \\
50 \% \text { of all sexual activities. / Safe word }\end{array}$ & $\begin{array}{l}\text { Having the submissive role as a slave in a master-slave role play- } \\
\text { ing. Does not enjoy much of the non-BDSM forms of sexual activity; } \\
\text { however still practices non-BDSM forms of sexual activity. Moderate } \\
\text { bondage, impact play, Impact play, BDSM lingerie and gadgets; forced } \\
\text { orgasm, being bitten, pain treatment, electricity; being chained and } \\
\text { locked; caged. Moderate pain involved but no marks and heavy impact } \\
\text { play. A short-term slave master relationship. No Severe BDSM. With } \\
\text { or without orgasms. More than a role play: Slave-master relationship; } \\
\text { BDSM practice and being submissive and slave give pleasure; arousal; } \\
\text { enhance orgasm. With or Without Orgasm / Affiliation to BDSM: at } \\
\text { least } 25-50 \% \text { / Affiliation to non-BDSM activities: } 50-75 \% \text {. / BDSM is } \\
\text { one of the most arousing activities / Safe word is considered. }\end{array}$ \\
\hline $\begin{array}{c}12 \\
\text { Intm } \\
\text { D }\end{array}$ & $\begin{array}{l}\text { Intermediate BDSM Level-D } \\
\text { Practiced in real life. / BDSM activity } \\
\text { frequency at least } 50-75 \% \text { of all sexual } \\
\text { activities. / Safe word }\end{array}$ & $\begin{array}{l}\text { Having the submissive role as a slave in a master-slave permanent } \\
\text { relationship. Does not Enjoy MUCH the non-BDSM forms of sexual } \\
\text { activity; however still practices non-BDSM forms of sexual activity } \\
\text { (less than } 50-75 \% \text { of all sexual activities). Heavy bondage, impact } \\
\text { play, BDSM lingerie and gadgets; forced orgasm, being bitten, pain } \\
\text { treatment, electricity; being chained and locked; caged. / Pain in- } \\
\text { volved with marks and heavy impact play. / A long term slave master } \\
\text { relationship. No Severe BDSM. / With or Without Orgasm /Affiliation } \\
\text { to BDSM: at least } 50-75 \% \text { / Affiliation to non-BDSM activities: } 50 \% \\
\text { at much. / BDSM is one of the most arousing activities and a way to } \\
\text { reach climax. / Safe word is considered. }\end{array}$ \\
\hline $\begin{array}{c}13 \\
\text { Adv } \\
\text { A }\end{array}$ & $\begin{array}{l}\text { Advanced BDSM Level-A } \\
\text { Practiced in real life. / BDSM activity } \\
\text { frequency is } 75-100 \% \text { of all sexual } \\
\text { activities / Safe word }\end{array}$ & $\begin{array}{l}\text { Advanced BDSM } \\
\text { A long term master-slave activity. } \\
\text { Safe word is considered is considered and applied. } \\
\text { Not } 7 / 24 \text { slave, but part-time slave. } \\
\text { Her/his orgasms are not important. Without or with Orgasm }\end{array}$ \\
\hline $\begin{array}{c}14 \\
\text { Adv } \\
\text { B }\end{array}$ & $\begin{array}{l}\text { Advanced BDSM Level-B } \\
\text { Practiced in real/ BDSM activity fre- } \\
\text { quency is } 99-100 \% \text { / Safe word }\end{array}$ & $\begin{array}{l}\text { Advanced BDSM } \\
\text { A long term master-slave activity. / Safe word is considered and } \\
\text { applied. / A full time slave-master relationship which is Practiced at } \\
\text { 7/24. / Her/his orgasms are not important. Without Orgasm }\end{array}$ \\
\hline $\begin{array}{c}15 \\
\text { Adv } \\
\text { C }\end{array}$ & $\begin{array}{l}\text { Advanced BDSM Level-C } \\
\text { Practiced in real life continuously } \\
\text { BDSM activity frequency is } 99-100 \% \text { No } \\
\text { Safe Word }\end{array}$ & $\begin{array}{l}\text { Advanced BDSM-Lifelong commitment. } \\
\text { A long-term master-slave activity. / A full time slave-master relation- } \\
\text { ship which is Practiced at } 7 / 24 \text { / No safe word }\end{array}$ \\
\hline
\end{tabular}


In Table 4, we have designed a preliminary Masochistic Behavior Scale (MasBS) to determine the levels of BDSM. The first 10 levels of MasBS do not have the items of being diagnosed as pathological and paraphilic. Level 11 is also questionable and debatable to be diagnosed as par-aphelia or perversion; they are intermediate levels, where not much physical or psychological harm is given to the victim. However, according to our above universal criteria of paraphilia, Levels, $12,13,14,15$, which fit to the definition of DSM5 and our above criteria can be called as paraphilia. Thus, more extensive surveys and classifications should be made to develop a scale for paraphilia and BDSM practices.

What should be done to establish a more objective and scientific DSM classification and particular scales for BDSM? a. More surveys among so-called normal sexual behavior

b. More surveys among BDSM sub-cultures to understand the attitudes and behavior

c. More neuroscience and fMRI, PET, EEG imaging research on normal and BDSM people

d. More research on BDSM behavior to determine, at what level BDSM is a SEPO, at what level it may become pathological. What are the criteria of being pathological?

e. More research on hypersexuality and increased libido

f. Neurochemistry and neuropharmacology research on sexual behavior, SEPOs, sexual variations, mild and hard BDSM

\section{ESR, sex addiction, pathological hypersexuality, non-pathological hypersexuality and nymphomania}

Table 5: The Main characteristics of women with ESR and expanded orgasm experience.

The ESR women experienced vaginal, clitoral and blended orgasms, as described by Ladas et al.

The ESR women experienced multiple orgasms in most of their sexual activities.

The ESR women were able to attain long lasting and/or prolonged and/or multiple and/or sustained orgasms and/or status orgasmus that lasted longer than the classical single orgasm and/or multiple orgasm patterns defined in the literature.
ESR women described a phenomenon called G-Spot orgasms.

ESR women described sensitive erogenous zones in their genitalia other than clitoris.

The ESR women were measured to have to have strong pelvic floor muscles (PFM) compared to NESR women; Kegel Perineometer measurement showed that their PC muscle strength was $>20$ milibars.

ESR women masturbated more frequently compared to NESR women.

ESR women had erotic fantasies more frequently than the NESR women.

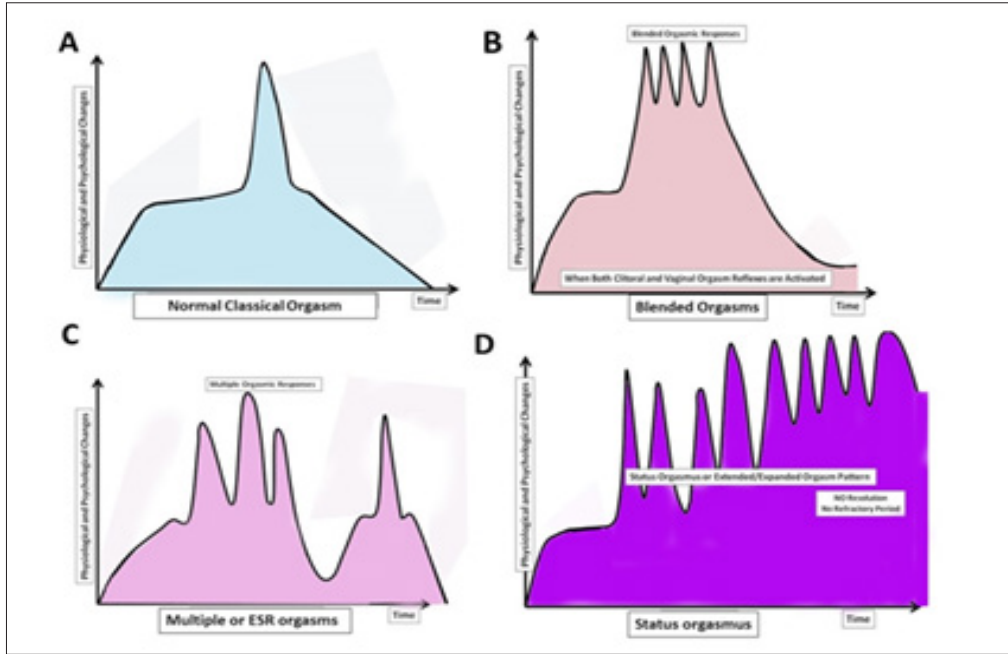

Figure 1(A): Classical female orgasm pattern, defined in the classical medical literature.

1(B): Multiple female orgasm pattern.

1(C): Blended female orgasm pattern.

1(D): Prolonged expanded orgasm or status orgasms. In the figure, $\mathrm{X}$ axis is time; $\mathrm{Y}$ axis depicts the classical patterns of physiological changes and pleasure as drawn in the classical sex therapy books. In blended orgasms there are many orgasm contractions coming from either clitoral or vaginal erogenous zones, which form separate peaks. Pleasure in blended and multiple ESR orgasms are more intense than that of one single orgasm. During status orgasms, there is a non-stop continuous orgasming pattern, lasting for minutes or tens of minutes, while the woman attains a train of orgasms as long as she is stimulated. 


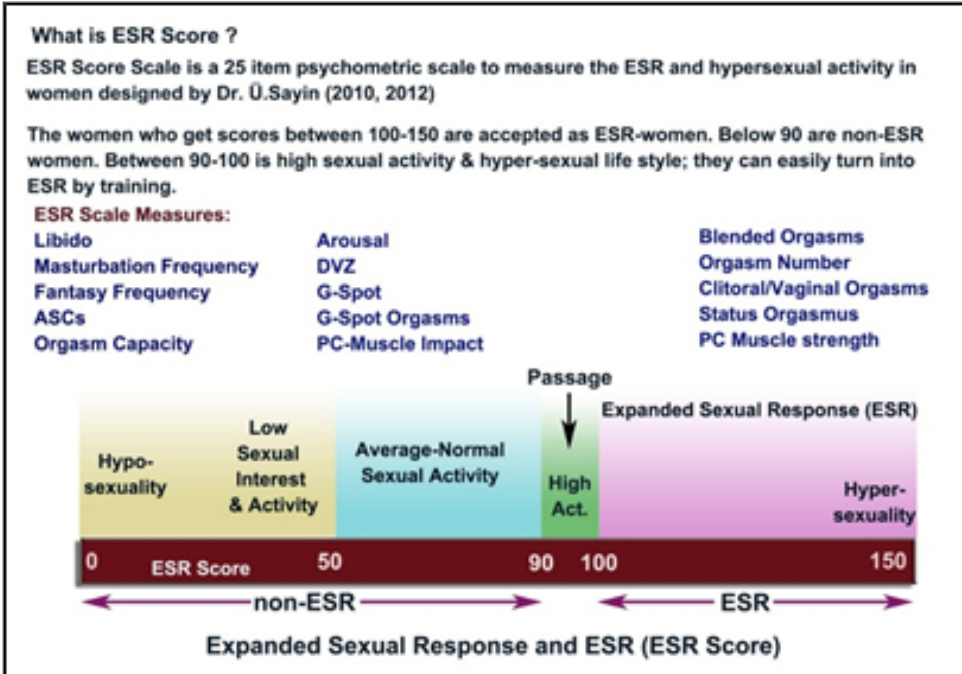

Figure 2: ESR Scores in the ESR Scale to measure the ESR level of women designed by Dr. Ümit Sayin [1-4].

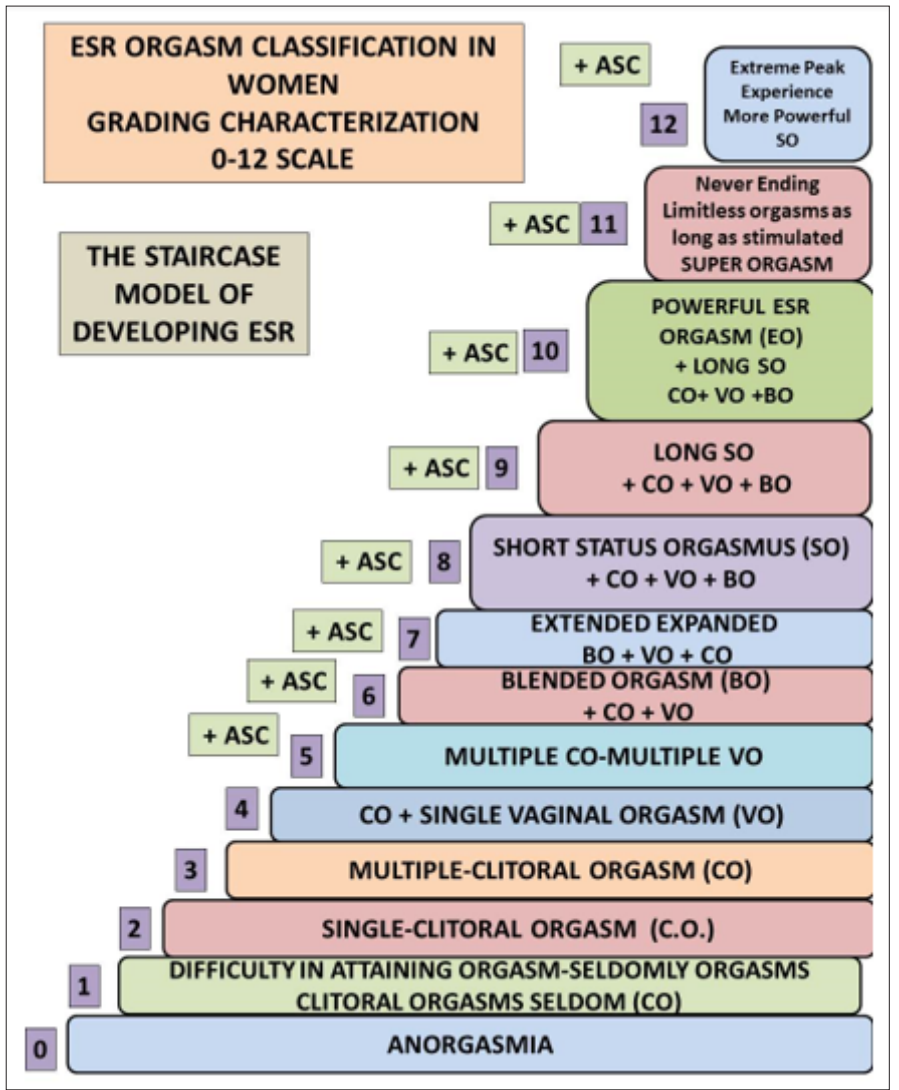

Figure 3: Staircase model of developing ESR. ESR orgasm classification in women and grading them according to the capacity and level of attaining different kinds of orgasms.

We have recently defined Expanded Sexual Response (ESR) in various scientific meetings and papers after an international ongoing survey, which is still continuing [1-5;67-70]. ESR has been defined as: "being able to attain long lasting and/or prolonged and/ or multiple and/or sustained orgasms and/or status orgasmus that lasted longer and more intense than the classical orgasm patterns defined in the literature". In the Eastern, Chinese, Indian and Tantric literature similar enhanced orgasmic experiences of females have been reported as well as some Western reports of the last decades (Table 5, Figures 1-3). Other definitions we have presented include as follows (Figure 1): Single Female Orgasm: Clitoral or vaginal orgasms. Clitoral orgasm is mediated by prudential nerve; vaginal orgasm is mediated by pelvic nerve. It has long been debated that some vaginal orgasms are triggered by Greenberg's Spot (G-Spot) [71]. Clitoral orgasm is generally perceived in a local genital area, as bursting; 80 to $90 \%$ of women have experienced it. Vaginal orgasms 
are said to be more satisfactory and more radiating occurring in 30 to $35 \%$ of the female population according to Hite and Cosmo Reports [31,32]. Multiple Orgasms: Multiple orgasms can be either clitoral or vaginal or induced by both. There is a successive train of orgasms, generally increasing in amplitude and intensity gradually.

Blended Orgasms: Blended orgasms can be mediated by the orgasm triggering mechanism of both clitoris and spots of vaginal origin (DVZ: such as G-Spot, A-Spot, O-Spot, PFM or Cervix). A blended orgasm is much more intense than a clit-oral or vaginal orgasm alone. Both prudential and pelvic nerves mediate the triggering of blended orgasm. Blended orgasms are much more satisfactory, and they are multiple orgasms. [65,71].

\section{Definition of status orgasmus}

Status orgasmus is the continuous form of blended orgasms and/or clitoral/vaginal orgasms that last for starting from 1 minute to 10-15 minutes (or more). During status orgasmus a continuous orgasmic state is experienced and very few women are believed to achieve status orgasmus state. Status orgasmus can be seen in vaginal and clitoral orgasms, however mostly it is seen as an expanded/extended form of blended orgasms, in which both clitoral and vaginal orgasmus reflexes are triggered at the same time. Similar orgasmic states and full body orgasms are also defined in Tantric literature. The duration may change from woman to woman. Status orgasmus was first defined by Masters \& Johnson as lasting for 43 seconds in a woman in 1966. Today it is estimated that status orgasmus continues for 1 to 2 minutes, while it may last for 10 to 15 minutes, a pro-longed and extended orgasmic state which ends by a giant orgasm (Big-0) that gives a big relief and satisfaction at the end. In most of the status orgasmus experiences there is usually a refractory period of 10 to 15 minutes. The number of minor orgasms in a status orgasmus may exceed from 5-10 to 20-30 (some women claim that this quantity goes up to around 50). In status orgasmus it is thought that prudential, pelvic, hypogastric and vagal nerves mediate the triggering mechanism at the same time (Figure 1).

\section{Expanded orgasms and ESR}

Patricia Taylor, who defined expanded orgasms (EO) first time, reported that the EO or ESR (expanded sexual response) orgasm duration was 0.2 to 60 minutes in 22 female subjects [72,73]. In our studies and surveys between 2010 and 2019, we have come across many cases of EO; more than 120 cases filled our ESR scale as being ESR women [1-4]. The women who experienced ESR orgasms claimed that during a status orgasmus or prolonged ESR orgasm, which last-ed from a couple of minutes to 10-15 minutes or more, they had had 20 to 30 minor orgasms in a train of multiple orgasms [1-5]. These figures were beyond the known and the published limits and the normal recorded physiology of the female orgasms (Figure 1, 2) According to 'Cosmo Report' (1983) among 10000 American women, $14.8 \%$ of women could attain only one orgasm, $65.9 \%$ could have 2 to 5 orgasms, $13.4 \%$ could reach to 6 to 10 orgasms, while only $5.9 \%$ could attain 11 or more orgasms during one love making session [32]. Our surveys point out that
6.1\% (Kadınca Report, 1993; N=1534), 7.7\% (Hülya Report, 2003; $\mathrm{N}=706$ ) and 4.3\% (Istanbul Report, 2013-2017, continuing; $\mathrm{N}=$ 949) of Turkish women can attain more than 11 orgasms during a love making session [1-4]. Thus, in different cultures we have substantial data which confirms the existence of a group of nearly $4-7 \%$ of women who can attain more than 11 (up to 20 or more) orgasms in a couple of hours during one love making session. Depending on the data from many other worldwide surveys and our surveys directed us to have an estimate of developing ESR, "to be at the ranges of 10 to $15 \%$ in the women population" after a creating a mathematical model and various calculations of probability [1-3]. Besides, in many of the ESR cases, we have come to the conclusion that ESR orgasms can be learned and women can be trained to achieve prolonged ESR orgasms [75].

ESR women are not sex or orgasm addicts. ESR phenomenon is not pathological. Addiction to a habitation or behavior is another reflection of the personality, mental state and the psyche. The neurological and neuropharmacological mechanisms of sex addiction are the subject of another vast article. ESR is not a form of pathological sexual behavior. It is true that ESR women may be hypersexual; however, every hypersexuality case cannot be regarded as a pathology and paraphilia. There are some cultural biases for women being hypersexual or multi orgasmic, that was, probably, one of the reasons why some American psychiatrists tried to propose a "Hypersexual disorder" and its criteria as "HDSI" into DSM-5 in 2013. However, we do not yet know the physiology and extents of female sexuality which has been started to be investigated for the last five decades [24]. It is a general belief that a woman can attain one orgasm, as much as a man and that is fine and enough; however, the recent data, being collected from various regions of the globe, does not confirm this hypothesis. On the contrary, it seems that the women and men are not alike, when we consider the structure, mechanism, female nerve innervation, duration, intensity and number of orgasms. Actually, as objective scientists, we have to investigate the female sexual physiology more profoundly, before branding the women, who have hyperactive sexual lifestyles, with the title of "insatiable" or "nymphomaniac". After the year 2000, we have come across many reports claiming that some women can attain "limitless orgasms"; one of the results we have cited were 134 and 200 orgasms per hour and none of them were "persistent genital arousal disorder" (PGAD) [1-5].

In sex addiction, the women are addicted to pleasure and orgasm. They cannot control it. They give harm to their own or to others' psychology. They want to stop it, but they realize that they are unable to control their sexual drives and impulses. So, often hypersexuality is mixed with sex addiction, however, that is conceptual chaos; hypersexuality is a totally different phenomenon. Nymphomania is also not sex addiction; nymphomaniac women generally have as many partners as they can have, they are also addicted to men, they cannot control their drives to have sex with men. Most of the time they are anorgasmic, so they cannot be regarded as an orgasm addict; they get pleasure but do not reach climax. Nymphomania is generally accompanied with another personality disorder, such as 
borderline, histrionic, paranoid, narcissistic personality disorders, or a psychiatric disorder, such as bipolar disorder, psychotic episodes, schizophrenia, mania, obsessive compulsive disorder
[1-4,25]. Thus, ESR phenomenon, hypersexuality, sex addiction, pornography addiction, nymphomania are all different concepts and entities (Table 6).

Table 6: Comparison of two hypersexuality models: the features of non-pathological hypersexuality and the hypersexuality which may turn into a pathology.

\begin{tabular}{|c} 
Hypersexuality Not Pathological \\
\hline $\begin{array}{c}\text { They have very powerful and prolonged orgasms. They are } \\
\text { not orgasm or sex addicts. They have auto-control and do not } \\
\text { change partners continuously. }\end{array}$ \\
They have some ethical values. \\
They can develop ESR, however they control on their attitudes. \\
Theye no psychiatric disorders. \\
$\begin{array}{c}\text { Their sexual lives may be consistent (generally monogamous) } \\
\text { and they do not have inner conflicts due to their sexual lives. } \\
\text { They, generally, do not have one-night stand sexual relation- } \\
\text { ships. }\end{array}$ \\
$\begin{array}{c}\text { Their hypersexual private life is not reflected to their social life } \\
\text { and it does not give harm to the self in social affairs or business } \\
\text { life. }\end{array}$ \\
hypersexual woman, however they keep it discreet.
\end{tabular}

The overall hypersexual and sexually hyperactive lifestyle does not give harm to their lives.

They generally do not cheat on their lovers and husbands.

They do not like and follow one-night stand sexual relationships or occasional short-term relationships.

They are not addicted to pleasure, sex and orgasm.

They do not have, generally, other kinds of paraphilia in their hyperactive sexual lifestyles.

Their sexual lifestyles do not give psychological or physiological harm to the self and others.

They can get married and have a happy family life. They may become good mothers. They may have loving relationships.

They are not obsessed with sex and orgasm. They have other occupations and values.

Their SEPOs are at a great range. They have many fantasies.

They masturbate a lot (daily, or every other day). Most of their fantasies do not become real in life.

\section{Hypersexuality Which May Become Pathological}

They may develop prolonged and multiple orgasms. Generally, they are addicts of pleasure. They don't have much control and they may change partners continuously.

They can develop ESR; however, they may not have a control on their sexual behaviors. Their ethical values are lower.

Generally, their sexual behavior is accompanied with a personality disorder, such as borderline, histrionic or narcissistic personality disorders. They may have additional psychiatric disorders (e.g. bipolar disorder)

They may not be consistent. Their sexual lives may induce some inner conflicts. They may go after one-night stands (e.g. Histrionic personality disorder, bipolar disorder, manic disorder, schizophrenia, psychosis)

Their hypersexual behavior may be sometimes scandalous. It may give harm to the social interactions and social relationships or in business life.

Although they are content of their sexual lives; they may not be happy with their attitudes and consequences of their attitudes. They may have adaptation problems in the society and guilt feelings.

The overall hypersexual attitudes may give harm to their lives and social interactions.

They may cheat on their lovers and husbands after a while.

They may be fond of one-night stand sexual encounters. They may change their partners very fast. They have many short-term relationships; or they may have multiple partners.

They may eventually become addicted to pleasure, sex and orgasm; however, this is, most of the time, a reflection of their other psychological problems (e.g. personality disorders, histrionic or narcissistic p.d.; or psychiatric disorders such as bipolar disorder, mania, schizophrenia, psychosis etc.)

With some other personality or psychiatric disorders, one or a couple of paraphilias may be accompanied with hypersexual behavior.

Their sexual lifestyles may give harm to themselves, partners and others.

Most of the time they cannot continue a monogamous relationship and marriage. Generally, they are divorced a couple of times. They may not handle long term loving relationships.

They are generally obsessed with sex. They practice different sexual encounters continuously. They may become porn-addict.

Their SEPOs are at a great range. They have many fantasies. They masturbate a lot (daily, or every the other day). Some of their sexual fantasies may become real in life. 


\section{Conclusion}

There is confusion and chaos in the terminology of some extreme sexual behaviors. More rigid and solid definitions using global data on the specific paraphilia definitions. Some sexual variations, hypersexuality and ESR are often mixed with the universal concept of paraphilia, which is re-defined in this article, creating much confusion in the medical literature. The following items and concepts should be redefined and reorganized with proper psychometric scales, before labeling a particular behavior as paraphilia. (Table 7)

Table 7: The concepts and phenomena which should be re-defined in DSM and compared with paraphilias, after establishing proper psychometric scales and making the global surveys.

\begin{tabular}{|c|c|c|}
\hline Hypersexuality & Female Orgasms & Some Paraphilias \\
\hline Acceptable \& Normal Hypersexuality & Deep Vaginal Erogenous Zones (DVZ) & Fetishism \\
\hline Pathological Hypersexuality & Grafenberg Spot (G-Spot) & Voyeurism \\
\hline Expanded Sexual Response (ESR) & Vaginal-Coital Orgasms & Soft BDSM (not pathological) \\
\hline Sex Addiction & Blended Orgasms & Intermediate Soft BDSM (not pathological) \\
\hline Orgasm Addiction & Expanded Orgasms & Hard (severe) Pathological BDSM \\
\hline Nymphomania & ESR Orgasms & \\
\hline Sex Object (SO) & Status Orgasmus & \\
\hline Sexual Pleasure Object (SEPO) & Never Ending Orgasms (Super-Or- \\
\hline Sexual Quotient (SQ) & Tantric Orgasms & \\
\hline
\end{tabular}

\section{Acknowledgement}

I would like to thank Prof. C. Anton Ruck for reading the manuscript partially at different times and giving valuable suggestions. This study is supported by the funds of İstanbul University-Cerrahpaşa (IU-C) BAP and ASEHERT-CISEATED (www. ciseated.org).

\section{References}

1. Sayin HÜ (2012) Artırılmıs cinsel donum: ESR; kadİnlarda ultra orgasm (Expanded sexual response: ESR; ultra-orgasm in women), İstanbul: Tantra Akademi/Onur Publications, Turkey.

2. Sayin HÜ (2012) Doors of female orgasmic consciousness: New theories on the peak experience and mechanisms of female orgasm and expanded sexual response. Neuro Quantology 10(4): 692-714.

3. Sayin HÜ (2014) Cinsellikte farkli boyutlar (derin sex) (different dimensions of sexuality: deep sex), second expanded edition, two volumes) Second expanded-extended updated edition, 2 volumes. İstanbul: Tantra Akademi/Onur Publications, Turkey.

4. Sayin HÜ (2017) Kadın ve orgasm: Orgazm yöntemleri ve yeni cinsel terapi teorileri (Women and orgasm: Orgasm methods and novel sex therapy theories), İstanbul: Tantra Akademi/Onur Publications, Turkey.

5. Sayin HÜ (2017) Tantra, ESR and the limits of female potentials. SexuS Journal 2(3): 055-074.

6. Sayin HÜ (2017) Female orgasmic consciousness: New horizons. SexuS Journal 2(4): 117-145.

7. Sayin HÜ (2018) Cinsel beyin (sexual brain-sexual mind). İstanbul: Tantra Akademi/Onur Publications, Turkey.

8. Sayin HÜ, KocatÜrk A (2018) Expanded sexual response in the human female: The mechanisms of expanded orgasms in women. Sexus Journal 3(8): 533-548.

9. Ruck CAP (2018) Thracian mystery religions. Sexus Journal 3(10): 819854.

10. Ruck CAP (2019) Persia, haoma and the greek mysteries. Sexus Journal 4(11): 991-1034.
11. Chang J (1977) The tao of love and sex: The ancient chinese way to ecstasy. Dutton, New York, USA.

12. Chang J (1983) The tao of the loving couple: True liberation through the Tao. Dutton, New York, USA.

13. Schwartz L, Schwartz B (1999) The one-hour orgasm. St. Martin's Griffin, New York, USA.

14. Mumford J (2005) Ecstasy through tantra. (3 ${ }^{\text {rd }}$ edn), Minnesota: Llewellyn Pub, USA.

15. Sayin HÜ (2013) Resimli 100 soruda neo-tantra: Tantrik cinselliğin sirlarl, (illustrated neo-tantra in 100 questions: Secrets of tantric sexuality), İstanbul: Tantra Akademi/Onur Publications, Turkey.

16. Krafft-Ebing R (1886/1998) Psychopathia sexualis: A medico-forensic study translation by Franklin S Klaf, Arcade Publishing, New York, USA, p. 408.

17. Shindel AW, Moser C (2011) Why are the paraphilias mental disorders? J Sex Medicine 8(3): 927-929.

18. Moser C (2011) Yet another paraphilia definition fails. Arch Sex Behav 40(3): 483-485.

19. Moser C (2011) Hypersexual disorder: Just more muddled thinking. Arch Sex Behav 40(2): 227-229.

20. Moser C (2016) DSM-5 and the paraphilic disorders: conceptual issues. Ach Sex Behav 45(8): 2181-2186.

21. Moser C (2017) ICD-11 and gender incongruence: language is important. Arch Sex Behav 46(8): 2515-2516.

22. Moser C (2018) Paraphilias and ICD-11: Progress but still logically inconsistent. Arch Sex Behav 47(4): 825-826.

23. Moser C (2019) DSM-5, Paraphilia and the paraphilic disorders: Confusion reigns. Arch Sex Behav 48(3): 681-689.

24. Sayin HÜ, KocatÜrk A (2019) APA'S DSM-5 HDSI proposal re-assessed: female perspectives. SexuS Journal 4(11): 979-990.

25. Sayin HÜ (2016) Parafili-1: Sexual disorders and normal female behavior (Paraphilia 1: Sexual disorders and sexual behavior beyond normal); Textbook. İstanbul: Tantra Akademi/Onur Publications, Turkey. 
26. Diagnostic and statistical manual of mental disorders: DSM-IV (2000) American psychiatric association, Washington, DC, USA.

27. American Psychiatric Association (2013) Diagnostic and statistical manual of mental disorders. In: Arlington VA ( $5^{\text {th }}$ edn), American Psychiatric Press, USA.

28. Comfort A (1978) Sexual idiosyncrasies: Deviation or magic. Journal of Psychiatry 9: 11-16.

29. Escapa R (1989) Bizzare sex, Grafton Books, London, UK, pp. 66-71.

30. Ellis H (1933-2014) Studies in the psychology of sex. Home farm books, New York, USA.

31. Hite S (1974) The hite report, Bantam Books, New York, USA.

32. Wolfe Linda (1982) The cosmos report, Corgi Books, London, UK.

33. Reinsisch June (1991) The kinsey institute new report on sex: St. Martin's Press, New York, USA.

34. (2016) New kinsey report findings.

35. Brown RE (1974) Sexual arousal, the coolidge effect and dominance in the rat (Rattus norvegicus). Animal Behav 22(3): 634-637.

36. Lester GL, Gorzalka BB (1988) Effect of novel and familiar mating partners on the duration of sexual receptivity in the female hamster. Behav Neur Biol 49(3): 398-405.

37. Dewsbury DA (2000) Frank a beach, master teacher. Portraits of Pioneers in Psychology, pp. 269-281.

38. Fiorino DF, Coury A, Phillips AG (1997) Dynamic changes in nucleus accumbent dopamine efflux during the coolidge effect in male rats. Neurosci 17(12): 4849-4855.

39. Tlachi-López JL, Eguibar JR, Fernández-Guasti A, Lucio RA (2012) Copulation and ejaculation in male rats under sexual satiety and the coolidge effect. Physiol \& Behav 106(5): 626-630.

40. Sayin HÜ, KocatÜrk A (2018) Expanded sexual response in the human female: The mechanisms of expanded orgasms in women. SexuS Journal 3(8): 533-548.

41. Morris D (2006) Çıplak kadın (Naked Woman). İstanbul: İnkilap Yayınevi, pp: 292-296.

42. Christensen HT (1962) A cross-cultural comparison of attitudes toward marital infidelity. Int J Comp Sociol 3(1): 124-137.

43. Greeley A (1994) Marital infidelity. Society 31(4): 9-13.

44. Janus S, Janus C (1993) The janus report on sexual behavior: John Wiley \& Sons Hoboken, New Jersey, USA.

45. Goleman D (2005) Emotional intelligence. $10^{\text {th }}$ anniversary edition: Bantam Books, New York, USA.

46. Goleman D (1998) Working with emotional intelligence. Bantum Books, New York, USA.

47. Murphy KR (2014) A critique of emotional intelligence: What are the problems and how can they be fixed? Psychology Press, London, UK.

48. Brackett S, Marc AP (2006) Measuring emotional intelligence with the mayer-salovery-caruso emotional intelligence test (MSCEIT), Psicothema, Spain.

49. Kafka MP (2010) Hypersexual disorder: A proposed diagnosis for DSM-V. Arch Sex Behav 39(2): 377-400.

50. Winters J, Christoff K, Gorzalka BB (2010) Dysregulated sexuality and high sexual desire: distinct constructs? Arch Sex Behav 39(5):10291043.
51. Wakefield JC (2012) The DSM-5's proposed new categories of sexual disorder: The problem of false positives in sexual diagnosis. J Clin Soc Work 40(2): 213-223.

52. Winters J (2010) Hypersexual disorder: A more cautious approach. Archives of sexual behavior 39(3): 594-596.

53. http://supervert.com/cgi-bin/survey/survey.cgi?survey_name=sexual_ perversity last accessed on May 2016.

54.Wismeijer AA, van Assen MA (2013) Psychological characteristics of BDSM practitioners. J Sex Med 10(8): 1943-1952.

55. Sayin HÜ (2019) Getting high on dopamine: Neuroscientific aspects of pleasure: Part-1: SexuS Journal 4(11): 883-906.

56. Sayin HÜ and Schenck C (2019) Neuroanatomy and neurochemistry of sexual desire, pleasure, love and orgasm. SexuS Journal 4(11): 907-946.

57. Mirolli M, Mannella F, Baldassarre G (2010) The roles of amygdala in the affective regulation of body, brain and behavior 22 (3): 215-245.

58. https://www.devianceanddesire.com/2016/01/altered-statesconsciousness/

59. Sayin HÜ (2019) A schematic overview of addiction: molecular effects of cocaine, methamphetamine and morphine on limbic neurons. Forensic Sci Add Res 4(4): 1-11.

60. Pukall CF, Strigo IA, Binik YM (2005) Neural correlates of painful genital touch in women with vulvar vestibulitis syndrome. Pain 115(1-2): 118127.

61. Casey KL, Minoshima S, Berger KL (1994) Positron emission tomographic analysis of cerebral structures activated specifically by repetitive noxious heat stimuli. J Neurophysiol 71(2): 802-807.

62. Casey KL, Morrow TJ, Lorenz J, Minoshima S (2001) Temporal and spatial dynamics of human forebrain activity during heat pain: analysis by positron emission tomography. J Neurophysiol 85(2): 951-959.

63. Whipple B, Komisaruk BR (1985) Elevation of pain threshold by vaginal stimulation in women. Pain 21(4): 357-367.

64. Steinman JL, Komisaruk BR, Yaksh TL, Tyce GM (1983) Spinal cord monoamines modulate the anti-nociceptive effects of vaginal stimulation in rats. Pain 16(2): 155-166.

65. Komisaruk BR, Beyer-Flores C, Beverly W (2006) The science of orgasm, baltimore: John Hopkins University Press, Baltimore, Maryland, USA.

66. Jannini EA, Wise N, Frangos E, Komisaruk BR (2018) Peripheral and central neural bases of orgasm. In: Sue w Gold Stein, Noel N Kim, Anita H Clayton, John Wiley \& Sons, (Eds.), textbook of sexual function and dysfunction: Diagnosis and treatment, ( $1^{\text {st }}$ edn), New York, USA, pp.179195.

67. Sayin HÜ (2010) Deep Sex: Different dimensions and openings of sexuality (Derin Seks: Cinsellikte Farklı Boyutlar, Yeni Açılımlar), İstanbul: Klan Publications, Albania.

68. Sayin HÜ, Ramstadius M, KocatÜrk A (2011) Expanded desire: The main parameters and new definitions of enhanced and Expanded Sexual Response (ESR). The $33^{\text {rd }}$ NACS Conference 2011, Oslo, Norway, Europe.

69. Sayin HÜ, Ramstadius M, KocatÜrk A (2011) Pelvic floor muscle strength is correlated with attaining vaginal orgasms in human female as measured by kegel perineometer. The $33^{\text {rd }}$ NACS Conference 2011, Oslo, Norway, Europe.

70. Sayin HÜ (2011) Altered states of consciousness occurring during expanded sexual response in the human female: preliminary definitions. Neuroquantology 9(4): 882-891.

71. Ladas AK, Beverly W, Perry JD (1982) The G-Spot and other discoveries about human sexuality, Henry Holtan company, New York, USA. 
72. Taylor P (2002) Expanded orgasm, Soar to ecstasy at your lover's every touch, Sourcebooks, New York, USA.

73. Taylor P (2000) PhD Thesis: An observational and comparative study of practitioners of expanded orgasm: An investigation of an effective and accessible path to transcendent states of consciousness, submitted in partial fulfillment of the requirements for the degree of philosophy in transpersonal psychology, International university of professional studies, Maui, Hawaii.
74.Armagan N, Sayin HÜ, KocatÜrk A (2012) Can sexual response be enhanced and expanded in the human female: Preliminary findings and a proposed psychometric scale for expanded sexual response (ESR). $38^{\text {th }}$ annual meeting of IASR (International academy of sex research), LisbonPortual, Portugal.

75. https://www.youtube.com/watch?v=hpc2NjUAtOY\&list=PLz5HIXzZPRxn9WDe_UUKd60m9i7_HCEYf\&index=7 